\title{
Designing and evaluation procedures for interdisciplinary building information modelling use - an explorative study
}

\author{
IVA KOVACIC $^{1 *}$ and MICHAEL FILZMOSER ${ }^{2}$ \\ ${ }^{1}$ Department for Industrial Building and Interdisciplinary Planning, Institute of Interdisciplinary Construction Process \\ Management, Vienna University of Technology, Karlsplatz 13 e234/2, 1040 Vienna, Austria \\ ${ }^{2}$ Institute for Management Sciences, Vienna University of Technology, Theresianumg. 27, 1040 Vienna, Austria
}

(Received 18 August 2014; accepted 15 November 2014)

Building information modelling (BIM) tools are increasingly present in the architecture, engineering and construction industry. This software tool chain requires not only new knowledge on the level of technology, but also people with knowledge related to skills and re-configuration of the process. There is hope that BIM tools will increase the degree of process integration and support the multidisciplinary planning practice. In order to test this assumption and gain first insights in multidisciplinary collaborative planning process using various BIM tools, an experimental study in a university course on multidisciplinary design was carried out. The results of our analyses indicate that BIM software is perceived as highly useful but not interoperable. The lack of interoperability and resulting problems are also the main topic of focus group discussions conducted after the course. Architects are less satisfied with the interdisciplinary planning process. Early coordination, concerning organization and software, proved positive for later collaboration.

Keywords: BIM, interdisciplinary planning, process integration, experiment.

\section{Introduction}

The architecture, engineering and construction (AEC) industry faces a need for integrated planning procedures that enable efficient collaboration and knowledge sharing among the disciplines involved. Building information modelling (BIM), that is, the joint usage of digital building models throughout the building life cycle by the involved actors, is argued, in practice and academia, to enable collaborative planning by facilitating communication and information exchange between diverse participants in the planning process. The usage of BIM should improve efficiency and quality significantly, while reducing the planning time simultaneously.

BIM is expected to bear a large potential for the enhancement of design integration, thereby enabling a shift from fragmented design tradition that is still largely dominating the AEC industry (Fellows and Liu, 2012). Advantages of BIM can be identified on two levels-real and virtual. In real world, through software and model interoperability, project-value is increasing along the fragmented AEC value chain, enabling the communication and collaboration of different tools and stakeholders. On the virtual level, simulation and therefore optimization of construction process is possible in the early design phases, at still low cost (Grilo and Jardim-Goncalves, 2010).

Rekola et al. (2010) argue that integrated design is still handled rather loosely in practice-often the creation of single BIM model is sufficient for the project to be referred to as integrated project, regardless of actual interdisciplinary data sharing and model use. Former BIM research has largely focused on solving of technical issues related to the data exchange and creation of functional interfaces. However, current research emphasizes that process-knowledge beyond technological issues, like workflow management and business practice accommodate the actual benefits of BIM. Rekola et al. (2010), for example, identify problems and benefits of

*Author for correspondence. E-mail: iva.kovacic@tuwien.ac.at

(C) 2014 Taylor \& Francis 
BIM-supported integrated planning processes in the following areas: (i) people (competence or knowledge problem), (ii) process (work-flow, timing, contracts, roles) and (iii) technology (software). They argue that for enhanced integrative practice an interrelation of people, process and technology is compulsive. The lack of knowledge of BIM-supported process and related people-problems in their opinion causes the slow BIM adoption that can currently be observed in practice. Moum (2010) goes even further in her study of five-design team stories using 3D BIM in an interdisciplinary setting, claiming that technology issues are secondary, and non-technological issues are the central problem in BIM-supported design. The nature of architectural design, based on tangible 'baking bread' and intangible 'playing jazz' capabilities, makes the successful and efficient BIM tools implementation particularly difficult, in which technology usability, user behavior and team interactions are interlaced in multiple ways and require careful balancing across these two processes.

BIM is experiencing a slower rate of implementation in Europe than in the USA, especially in Central Europe (McGraw-Hill Construction, 2010). Given the lack of best practices in the Central European planning tradition (involving architects, planners and contractors), we decided to accomplish an explorative study to explore potentials and deficits of BIM in the multidisciplinary design process within design studio class with student participants. BIM in teaching is already a relatively well-established method, especially in the field of construction management. Peterson et al. (2011) focus on teaching project management methods using BIM tools, in single-disciplinary setting, extracting project management relevant data (scheduling, masses for costs) from architectural models and transferring the data in various project-management tools. Hyatt (2011) uses BIM tools for scheduling, LEED certification scheduling and 4D simulation. Both authors, Peterson et al. and Hyatt conclude that 'real' tools are of significant importance-the work experience in the first case or the field trip experience in the second are the crucial factors for learning or grasping of optimization potential of a project much more than technology. Poerscheke et al. (2010) study multidisciplinary design (architecture, landscaping, structural, construction, mechanical and electrical engineering) in which students optimize a given pre-design of an elementary school in collaborative manner for usability, sustainability and so on. The intention of this research is twofold: to test BIM tools for fitness for each discipline on the one hand and the interdisciplinary collaboration on the other. They conclude that BIM and simulation tools are useful for enhancement of analysis and synthesis but do not enhance creativity, the actual driver for idea-generation is the interdisciplinary collaboration. Plume and Mitchell (2007) test in their course the interoperability of BIM tools via the IFC interface, again using given preliminary projects. Students of various disciplines perform cost estimation, thermal simulation, and acoustic analysis using a common model via an IFC model server. This course dates back to winter term 2004, where the technical possibilities of the main modelling tool, ArchiCad - the supported IFC version - were still limited, and many of the addressed problems, such as versioning, have been solved. However, many of the problems of the semantic nature still remain unsolved-for example, the definition of the 'room' being different for architects and building physicist. (Kovacic et al., 2013). Dossick et al. (2012) focus on the analysis of communication and creation of new knowledge in spatially distributed student teams that collaborate in a virtual environment, compiling $4 \mathrm{D}$ scheduling and organizational analysis. In this domain, modelling in real time actually supports the messy talk and thereby increases creativity.

None of the above discussed BIM teaching approaches focuses or actually deals with the process of initial, collaborative building design. These instead apply either prefabricated building models and designs or in later design phases where the architectural design is completed, and architectural model serves as a knowledge base for project management tasks (scheduling, cost management). There is still lack of knowledge about the creation of the initial building design, its simulation and optimization in a collaborative manner using the various BIM tools to support both the improvement of the building quality and the planning process quality.

\section{Research design}

In the evaluation of BIM performance in multidisciplinary design process, we primarily aimed at examining the role of BIM in the integrated design process in the earliest stage, in which the architectural model is initially created including structural predesign and energy (HVAC) concept. Further aim was to examine the fitness of BIM tools for requirements of each discipline concerning data-exchange. Thereby, both technical issues, such as usefulness of tools and interoperability in heterogeneous software environment, as well as non-technical issues such as diverging professional languages and semantics, communication and organization, play equally important roles. As framework for the evaluation, the triangle 'technology-peopleprocess' was used, as research shows that despite the focus on development of technology in BIM research (software interoperability, advancement of singular 
Table 1 BIM tool constellations

\begin{tabular}{|c|c|c|c|c|c|}
\hline \multirow{2}{*}{ Team } & \multirow{2}{*}{$\begin{array}{c}\text { Architectural model } \\
\text { CAD }\end{array}$} & \multirow{2}{*}{$\begin{array}{l}\text { Structural model } \\
\text { CAD }\end{array}$} & \multirow{2}{*}{$\begin{array}{l}\text { Engineering } \\
\text { FEM }\end{array}$} & \multicolumn{2}{|c|}{$\begin{array}{l}\text { Building science (thermal } \\
\text { simulation: TAS; energy } \\
\text { performance certificate: } \\
\text { Archiphysik; daylight } \\
\text { simulation: Dialux) }\end{array}$} \\
\hline & & & & CAD & Calculation \\
\hline 1 & Allplan & Allplan & Scia Engineer & Allplan & Allplan \\
\hline 2 & Revit & Revit & Sofistik & Revit & Plancal \\
\hline 3 & ArchiCAD & Tekla & Dlubal RFEM & Plancal & Plancal \\
\hline 4 & ArchiCAD & Allplan & Dlubal RFEM & Plancal & Plancal \\
\hline 5 & Revit & Allplan & Scia Engineer & Plancal & Plancal \\
\hline 6 & ArchiCAD & Allplan & Dlubal RFEM & Revit & Plancal \\
\hline 7 & Allplan & Tekla & Sofistik & Revit & Plancal \\
\hline 8 & Revit & Tekla & Scia Engineer & Allplan & Allplan \\
\hline 9 & ArchiCAD & Revit & Dlubal RFEM & Plancal & Plancal \\
\hline 10 & ArchiCAD & Allplan, Tekla & Dlubal RFEM & Revit & Plancal \\
\hline 11 & ArchiCAD & Tekla & Sofistik & Revit & Plancal \\
\hline
\end{tabular}

models, versioning and model sharing), the actual success of implementation largely depends on people (skills, understanding, capacities) and process (management strategy, process design) (Gu and London, 2010; Arayici et al., 2011; Singh et al., 2011).

For this purpose, we conducted an exploratory study with graduate students in a design studio class: 'Interdisciplinary Design Concepts using BIM'. A total of 39 students from architecture, structural engineering and building science collaborated in 11 multidisciplinary teams, each group used a different BIM software constellations. The design class was organized and supervised by three departments of the Vienna University of Technology: The Department for Industrial Building, Faculty of Civil Engineering, Department for Building Physics, Faculty of Architecture and the Department for Management Sciences, Faculty for Mechanical Engineering which were in charge of the evaluation of the experiment.

The teams were given an assignment of a sustainable office building design, for which they were provided with a functional program, site-plan with orientation and set origin, layer-structure and colour scheme for latter room-stamps. The students were assigned to teams-each featuring a different combination of BIM software for architecture, civil engineering and building science as shown in Table 1-according to their software experience based on a self-evaluation in a preexperiment questionnaire. Each team used a different combination of BIM-software for the architectural model, the modelling and calculation of load bearing structure and the thermal and daylight simulation, as well as ventilation calculation, simulation and modelling. The task of the teams was to deliver a preliminary integrated design, comprising architectural and functional designs, load-bearing structure, HVAC (ventilation) concept and energy concept together with a proof of concept (simulation and optimization)shown exemplarily for one of the groups in Figure 1. The teams had to deliver architectural, structural, thermal and ventilation models, as well as thermal simulation and energy certificate in collaborative manner.

\section{Teams and collaboration}

The class involved 13 architects, 11 civil engineers and 15 building physicists, working in 11 teams, each team comprising at least one of every discipline, several groups comprising 2 building scientists and 2 architects.

The time-schedule of the design-class was strictly organized-the course and experiment took one semester. The class was structured as succession of weekly feedback sessions, as well as two intermediate and one final presentation. The two intermediate presentations were at the point in time succeeding the interdisciplinary model exchange. The first presentation included the presentation of digital architectural model and of structural and energy concepts, the second included the architectural and structural models and energy simulation, and the final included the optimized integrated model with thermal simulation results. In between the weekly feedback sessions, the software training crash-courses took place, where supporting software vendors introduced the specific BIM software functionalities and provided data exchange support. 

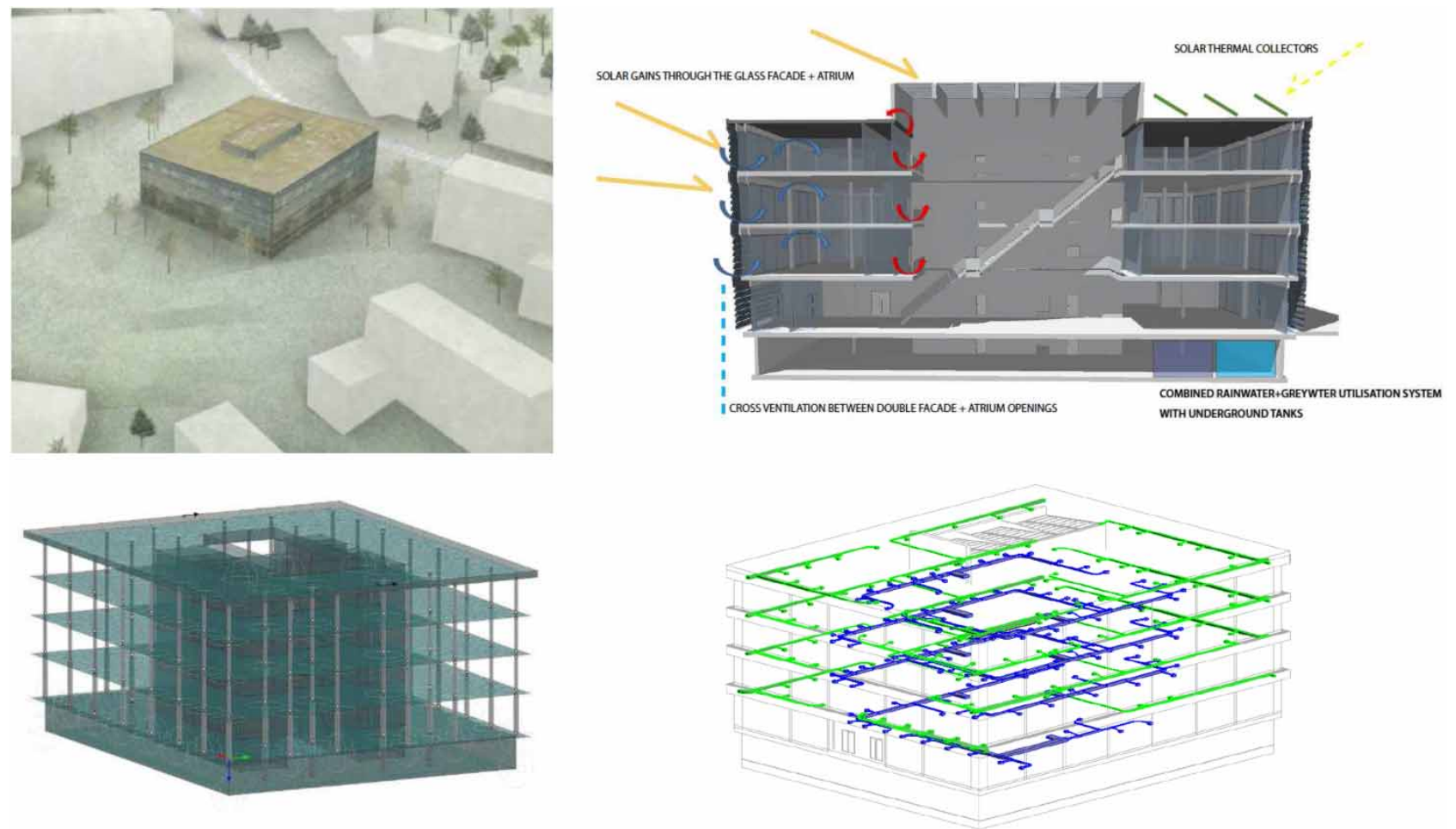

Figure 1 Exemplary resulting models of a student-project: architectural, structural, energy concept, ventilation

Besides to the software training, the students were given an introductory lecture on BIM basics and principles.

After assigning the students to the teams and to the task, the teams were left to themselves in terms of organization and coordination. The only obligatory meeting was the Friday discussion session, where attendance of the complete team was required, as well as the attendance of the two intermediate and one final presentation required.

\section{Results and discussion}

Our analyses of the technical and the interpersonal aspects of the multidisciplinary-integrated planning processes in the 11 groups of the experiment were based on the several data collected during and after the course. The experiment was evaluated on the level of people, process and technology, via protocols and time (self-)assessment, post-questionnaires concerning the BIM software and the BIM planning process and outcome, as well as focus group discussions with the representatives of the three disciplines after the experiment. Observations of the course instructors are addressed later in this section.

The students were keeping and delivering time reports not only to determine the efficiency, but also to allocate temporal resources spent on specific activities (communication, coordination, modelling, technical problems). Additionally, participants kept protocols which allowed not only to uncover problems related to the technology (data exchange, data transfer problems), but also people- and process-related issues (conflicts, communication difficulties, lack of workflow definitions, etc.).

The time reports included the time categories: software training, design (generating ideas, sketches, modelling), technical planning (analysis and calculation, model adaptation, preparation of the presentation), weekly feedback session, technical problems (online support of the vendors, model exchange related problems, model adaptation for import/export, problem solving) and organization (direct and indirect communication, meetings) - see Figure 2 for an exemplary Pareto-diagram of the total work time spent by one of the groups on these activity categories. The results for time assessment vary between groups; however, a consistent observation is that most of the time is used for the technical planning, followed by technical problems.

After the experiment, a questionnaire-based survey was conducted, as well as three focus group discussions, one with which each of the three disciplines architects, civil engineers and building scientists. A focus group is a qualitative research method in which groups of 


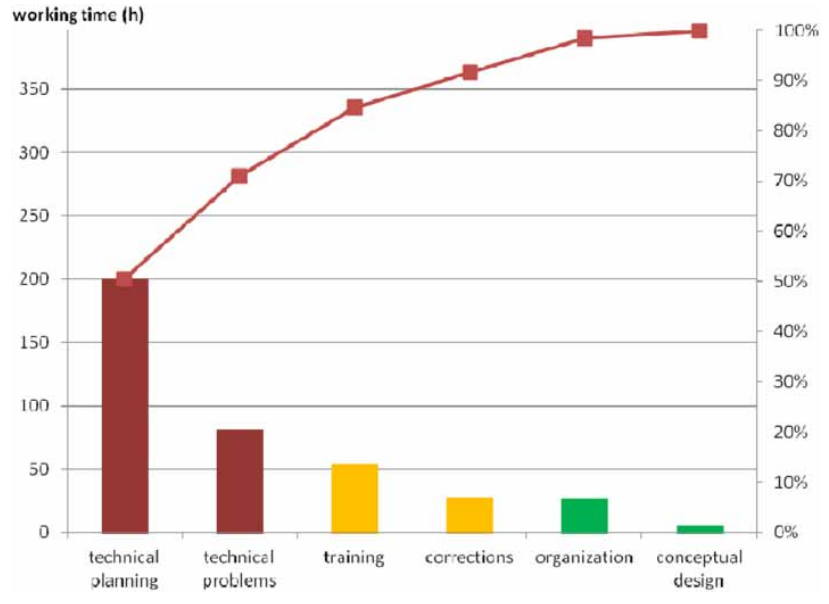

Figure 2 Exemplary Pareto-diagram of time assessment (Group 2)

people are asked about their perception, opinions, beliefs and attitudes towards products, concepts, ideas and so on (Marshall and Rossman, 1999). Questions are asked in an interactive setting and participants can freely talk with each other. The method originates from marketing research, but can also be used for usability engineering of software and web sides (Nielsen, 1993).
The focus group discussions were analysed by means of content analysis (Koeszegi and Srnka, 2007) by two independent coders in a four-step procedure. First the audio records were transcribed, followed by a separation of the whole content into thought units. In a third step, a category scheme was developed based on theoretical considerations (deductively) and the data at hand (inductively) (see Table 2). In a last step, the data is coded. The quality of steps two and four are controlled by statistically measuring the inter-coder unitizing and coding reliability to secure objectivity of the content analysis.

The results of this content analysis procedure are summarized in Figure 3. The focus group discussions showed that issues of interoperability dominated the focus groups. Early coordination (organization and software) proved positive for later collaboration. The positive experiences outweigh the negative, especially for the structural engineers and building science. This is intuitive, as these are the professions that benefit from BIM, even though they do not create the original BIM. Time pressure and stress were noted in later planning phases, which calls for carefully designed time and process management.

The post-questionnaires assessed satisfaction with process ('I have performed my tasks efficiently'), with result ('The aims that I have set have been achieved')

Table 2 Content analysis coding categories

\begin{tabular}{|c|c|c|}
\hline Category & Description & Example \\
\hline Ease of use & $\begin{array}{l}\text { Discussion concerning the ease of use } \\
\text { of BIM tools }\end{array}$ & 'So to perform a change in SCIA is super easy' \\
\hline Usefulness & $\begin{array}{l}\text { Discussion concerning the usefulness } \\
\text { of BIM tools }\end{array}$ & $\begin{array}{l}\text { 'I do not think it is good that it is possible to make a change in } \\
\text { SOPHISTIC, or that this is changed automatically' }\end{array}$ \\
\hline Interoperability & $\begin{array}{l}\text { Discussion concerning the } \\
\text { interoperability of BIM tools }\end{array}$ & $\begin{array}{l}\text { 'He gives a feedback back in REVIT. It says: 'there is a } \\
\text { problem with a building part' you have to have a look at it!' }\end{array}$ \\
\hline Training & $\begin{array}{l}\text { discussion of BIM and software } \\
\text { training }\end{array}$ & $\begin{array}{l}\text { 'Training helped, but I would not be able to learn a software, } \\
\text { without a project' }\end{array}$ \\
\hline Software support & Discussion of software support & $\begin{array}{l}\text { 'I had a mistake, as I wanted to make an opening in the slab } \\
\text { for the core, and the openings were not visible, and I have } \\
\text { asked the software support' }\end{array}$ \\
\hline Technical discussion & $\begin{array}{l}\text { (Detailed) discussion of technical } \\
\text { issues }\end{array}$ & 'What FE net size did you set?' \\
\hline General discussion & General discussion concerning BIM & ' $\mathrm{BIM}$ is gains increasing importance in practice, because ...' \\
\hline Negative collaboration & $\begin{array}{l}\text { Expression of negative experiences in } \\
\text { collaboration with other disciplines }\end{array}$ & 'Problems ... came up $(\ldots)$ with static' \\
\hline Positive collaboration & $\begin{array}{l}\text { Expression of positive experiences in } \\
\text { collaboration with other disciplines }\end{array}$ & 'But with the architect it worked very well, so $(\ldots)$ ' \\
\hline Suggestion & $\begin{array}{l}\text { Suggestions for general improvements } \\
\text { or solution of specific problems }\end{array}$ & $\begin{array}{l}\text { 'What could be useful when organizing a project like this } \\
\text { would be that architects have already finalized their part' }\end{array}$ \\
\hline Confirmation & Filler words and general acceptance & 'That is right' \\
\hline Misc. & Off topic discussions & - \\
\hline
\end{tabular}




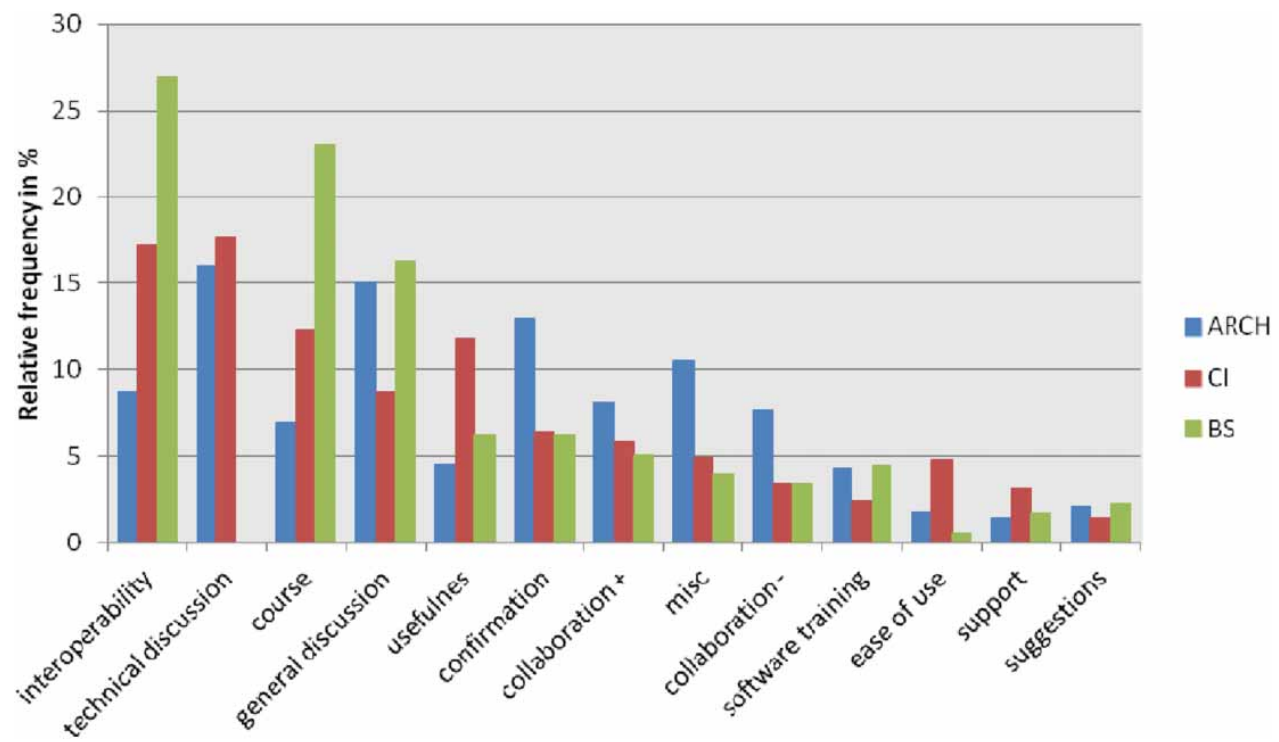

Figure 3 Content analysis of focus group discussions

and cooperation. The software-related questionnaire included questions related to ease of use ('The software increases my productivity'), and usability ('In total I think the software is useful for my tasks') according to technology-acceptance model (TAM) of Davis (1989) model and additionally interoperability as a BIM specific feature of software applications. These latent constructs where measured by multiple items on a 5point Likert scale ranging from low/disagree (1) to high/agree (5).

The satisfaction with the process and result is generally relatively high (see Figure 4) in all of the disciplines, however, architects (usually the creators of the original BIM model) are less satisfied with cooperation, which holds true at a lesser extent for the other roles, too. The focus group discussions demonstrated that issues of interoperability dominated the focus groups. Early coordination (organization and software) proved

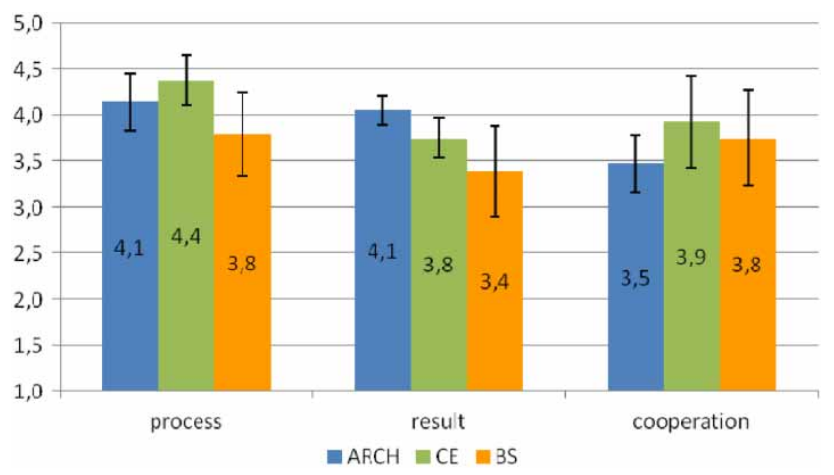

Figure 4 Results of the general questionnaire positive for later collaboration. The hypothesis that exclusively through the use of BIM tools the integrated planning would be enhanced was not affirmed. An integrated design process requires a careful process design involving teaming, design of communication and dataexchange beyond BIM technology in order to fully enhance the process integration.

The results of post-questionnaires concerning software acceptance (Figure 5) show that users assign BIM-software a high-perceived usefulness, lower ease of use and extremely low interoperability of different software solutions. This is especially true for civil engineers and building scientists. Interoperability is of the greatest importance for the structural engineers and building science students, since they extract the data from the original, architectural model, however, is judged as very problematic. Improving especially interoperability would have the strongest positive effect on

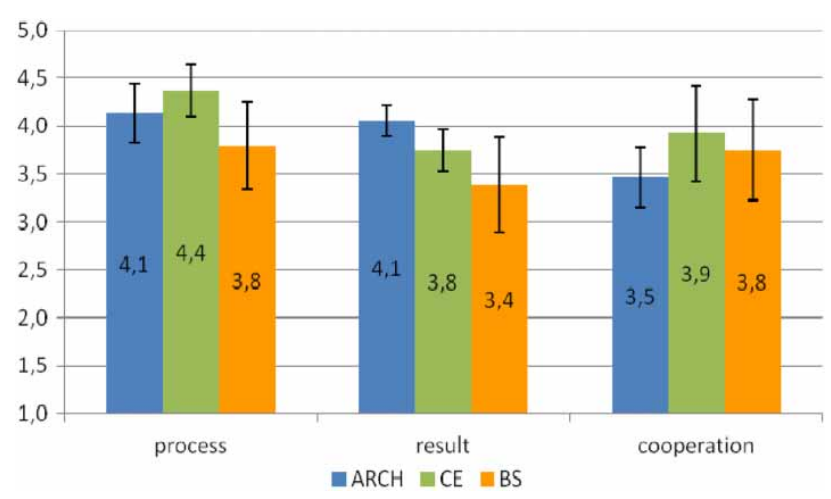

Figure 5 Results of the software questionnaire 
the acceptance of BIM-software according to our analyses.

Besides these analyses based on the data gathered from the groups, the course instructors and supervisors observed several aspects concerning the quality of design, workflow- organization and class administration during the weekly feedback discussions and the three presentations, which are discussed subsequently.

The students were primarily concerned with mastering the software, modelling and interdisciplinary data exchange, which resulted in projects of average or even below-average design quality. Due to the numerous difficulties in terms of interoperability and model exchange, many improvements of design were 'sacrificed' in order to minimize the necessary rework. In some cases, the design was not optimized as result of the consensus in the team to prevent additional calculation and simulation effort for the engineer or building scientist in the team. A further problem-though not just BIM-related, but rather related to software usage in general-concerning the outcome quality is the interpretation of results - the students are relying on the results generated by the software tools and often are not able to verify or interpret them. In some cases, manifold over- or under-dimensioning of the load bearing elements or generated heating loads in summer have not been reported as fault at presentations.

The work flow organization turned out as sequential design, despite the instructions and requirements to present integrated projects. In most of the groups, the architects started with the initial design and modelling, counting as model 'owners'. The disciplines that followed were expecting necessary model adaptations for failed data-exchange or design-improvement after the simulation or calculation to be carried out by the architect, as 'model owner/creator', which resulted with numerous conflicts. The 'teams' were not feeling as teams until the final presentation, which required the presentation and delivery of the integrated digital model. At this point in time, finally all of the team members felt working on a joint project, much more than only optimizing the architect's model. We assume that the lack of team-spirit and joint aim setting can be contributed to a required but missing kick-off meeting where teams could be initially formed.

The class involved cooperation of two faculties (civil engineering and architecture) and of three different disciplines (architecture and building science are both master curricula of faculty of architecture), which posed challenges for the involved course supervisors in terms of administration and organization. Numerous constraints on the schedule had to be considered due to the different curricula. The same holds true for the organization of the class as different course-management-platforms for each discipline were used. The administration of the class in terms of ECTS credits represented the main difficulty, because of the unbalanced reward of credits for each discipline. For the architects the class was offered as elective class rewarding 2 credits, for civil engineers as project class rewarding 4 credits and for building physics students as master project course rewarded 10 credits. The differences in course credits were compensated by additional tasks (reports, further analyses, etc.) but certainly influenced the effort and motivation of the participants. This disproportional reward represented a major issue for balancing of workloads within the teams and was resulting in many conflicts with both team members and faculty.

\section{Conclusion}

The assumption that exclusively through the use of BIM tools the integrated planning would be enhanced cannot be supported by the results gathered in the explorative experimental study we presented and discussed in this paper. The participants worked in a sequential manner especially in the first part of the experiment, where the architect was expected to provide an architectural design, as well as to create the architectural BIM. This model then was used by the successive disciplines for their subsequent modelling. Many conflicts and discussions arose on the issue of model management, changes and adaptation of the original model, which are necessary for the proper transfer into the subsequent engineering and thermal simulation. In general, the architect was expected to carry out all of the adaptations, which led to numerous conflicts-who has to do what and when?

The lack of team spirit and joint vision can be attributed to the lack of an organized, moderated kick-off meeting as well as to the lack of time and space for face-to-face student meetings and workshops. The expectation that student teams will be able to organize themselves for collaborative work without support was not affirmed.

The main challenge remains and the improvement of the quality of the projects should follow the maxim 'form follows function' instead of 'form follows tool'. Careful balancing of BIM tools usage and interdisciplinary design workshops involving traditional media such as model building, sketching and mapping could enhance a more creative way for finding innovative solutions, however, the optimization of results largely depends on experience and practical know-how of involved disciplines. In general, our results comply with the findings reported by Poerscheke et al. (2010), 
and the focus group discussions comply with practitioners focus groups (Gu and London, 2010).

After the pilot experiment in winter term 2012, we ran a second experiment in 2013. Lessons learned from the pilot experiment where incorporated in the design of this experiment: A designed process, including teaming workshop and a variety of integrated, intensive workshop phases and the phases where team members can work by themselves. Furthermore, more credits were assigned to the architectural students (5 credits), due to the reorganization of the studio and more support of the faculty administration. We plan to compare the results of the two instances, to gain more insight on (i) benefits of BIM for enhancement of integrated planning and (ii) on its impact of process-design on planning results (satisfaction, workflow, efficiency) as soon as the collected data is edited and evaluated.

\section{Acknowledgements}

We gratefully acknowledge the collaboration of the project partners, particularly of Institute for Building Physics, Faculty of Architecture, Vienna University of Technology, Prof. Ardeshir Mahdavi, Kristina Kiesel and Linda Skoruppa; as well as to the supporting partners from the industry: ANull, Artaker GmbH, b.i.m.m. Gasteiger, Nemetschek, Construsoft, Dlubal REFM, Plancal. We also thank our colleagues without whom this research would not be possible: Lars Oberwinter, Rüdiger Suppin, Christoph Müller and Prof. Christoph Achammer.

\section{Funding}

This research was funded by the FFG (Austrian Research Promotion Agency) [grant no. 836461].

\section{References}

Arayici, Y., Coates, P., Koskela, L., Kagioglou, M., Usher, C. and O'Reilly, K. (2011) Technology adoption in the BIM implementation for lean architectural practice. Automation in Construction, 20, 189-195.

Davis, F.D. (1989) Perceived usefulness, perceived ease of use, and user acceptance of information technology. Management Information Systems Quarterly, 13(3), 319-340.

Dossick, C., Anderson, A., Iorio, J., Gina Neff, G. and Taylor, J. (2012) Messy talk and mutual discovery: exploring the necessary conditions for synthesis in virtual teams. Engineering Project Organizations Conference, Rheden, The Netherlands.

Fellows, R. and Liu, A.M.M. (2012) Managing organizational interfaces in engineering construction projects: addressing fragmentation and boundary issues across multiple interfaces. Construction Management and Economics, 30(8), 653671.

Grilo, A. and Jardim-Goncalves, R. (2010) Value proposition on interoperability of BIM and collaborative working environments. Automation in Construction, 19, 522-530.

$\mathrm{Gu}, \mathrm{N}$. and London, K. (2010) Understanding and facilitating BIM adoption in the AEC industry. Automation in Construction, 19, 988-999.

Hyatt, A. (2011) A case study integrating lean, green, BIM into an undergraduate construction management sceduling. 47th ASC Annual International Conference Proceedings.

Koeszegi, S. \& Srnka, K. (2007) From words to numbers: How to transform qualitative data into meaningful quantitative results. Schmalenbach Business Review, 59, 29-57.

Kovacic, I., Oberwinter, L., Müller, C. \& Achammer, C. (2013) The "BIM-sustain" experiment - simulation of BIM-supported multi-disciplinary design. Visualization in Engineering, 1-13, 1-12.

Marshall, C., and Rossman, G.B. (1999) Designing Qualitative Research, 3rd edn, Sage, London.

McGraw-Hill Construction. (2010) The business value of BIM in Europe. Bernstein, H.M. (ed.), Smart Market Report.

Moum, A. (2010) Design team stories Exploring interdisciplinary use of $3 \mathrm{D}$ object models in practice. Automation in Construction, 19, 554-569.

Nielsen, J. (1993) Usability Engineering, Academic Press, Boston.

Peterson, F., Hartmann, T., Fruchter, R. \& Fischer, M. (2011) Teaching construction project management with BIM support: Experience and lessons learned. Automation in Construction, 20, 115-125.

Plume, J. and Mitchell, J. (2007) Collaborative design using a shared IFC building model-Learning from experience. Automation in Construction, 16, 28-36.

Poerscheke, U., Holland, R.J., Messner, J.I. and Philak, M. (2010) "BIM collaboration across disciplines", Proceedings of the International Conference on Computing in Civil and Building Engineering.

Rekola M., Kojima, J., and Mäkeläinen, T. (2010) Towards integrated design and delivery solutions: Pinpointed challenges of process change. Architectural Engineering and Design Management, 6, 264-278.

Singh, V., Gu, N., and Xiangyu Wang, X. (2011) A theoretical framework of a BIM-based multi-disciplinary collaboration platform. Automation in Construction, 20, 134-144. 